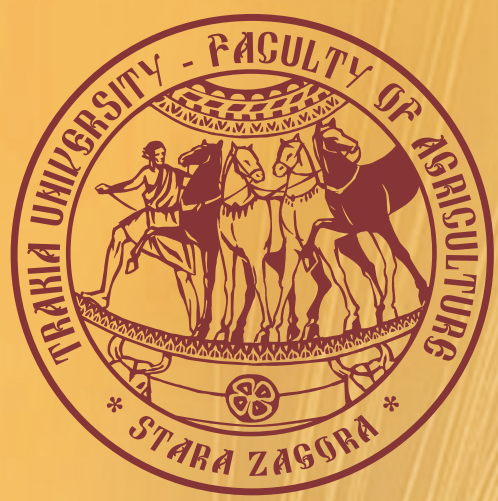

ISSN $1313-8820$ (print)

ISSN 1314 - 412X (online)

Volume 9 , Number 4

December 2017

\title{
AGRICULTURAL
}

\section{SCIENCE AND TECHNOLOGY}

\section{7}

An International Journal Published by Faculty of Agriculture, Trakia University, Stara Zagora, Bulgaria 


\section{Editor-in-Chief}

Georgi Petkov

Faculty of Agriculture

Trakia University, Stara Zagora

Bulgaria

E-mail: gpetkov@af.uni.sz.bg

\section{Co-Editor-in-Chief}

Dimitar Panayotov

Faculty of Agriculture

Trakia University, Stara Zagora

Bulgaria

\section{Editors and Sections}

\section{Genetics and Breeding}

Tsanko Yablanski (Bulgaria)

Atanas Atanasov (Bulgaria)

Svetlana Georgieva (Bulgaria)

Nikolay Tsenov (Bulgaria)

Max Rothschild (USA)

Ihsan Soysal (Turkey)

Horia Grosu (Romania)

Stoicho Metodiev (Bulgaria)

Bojin Bojinov (Bulgaria)

\section{Nutrition and Physiology}

Nikolai Todorov (Bulgaria)

Peter Surai (UK)

Ivan Varlyakov (Bulgaria)

George Zervas (Greece)

Vasil Pirgozliev (UK)

\section{Production Systems}

Radoslav Slavov (Bulgaria)

Dimitar Pavlov (Bulgaria)

Bogdan Szostak (Poland)

Banko Banev (Bulgaria)

Georgy Zhelyazkov (Bulgaria)

\section{Agriculture and Environment}

Martin Banov (Bulgaria)

Peter Cornish (Australia)

Vladislav Popov (Bulgaria)

Tarek Moussa (Egypt)

\section{Product Quality and Safety}

Stefan Denev (Bulgaria)

Vasil Atanasov (Bulgaria)

Roumiana Tsenkova (Japan)

\section{English Editor}

Yanka Ivanova (Bulgaria)
Scope and policy of the journal

Agricultural Science and Technology /AST/

- an International Scientific Journal of Agricultural and Technology Sciences is published in English in one volume of 4 issues per year, as a printed journal and in electronic form. The policy of the journal is to publish original papers, reviews and short communications covering the aspects of agriculture related with life sciences and modern technologies. It will offer opportunities to address the global needs relating to food and environment, health, exploit the technology to provide innovative products and sustainable development. Papers will be considered in aspects of both fundamental and applied science in the areas of Genetics and Breeding, Nutrition and Physiology, Production Systems, Agriculture and Environment and Product Quality and Safety. Other categories closely related to the above topics could be considered by the editors. The detailed information of the journal is available at the website. Proceedings of scientific meetings and conference reports will be considered for special issues.

\section{Submission of Manuscripts}

There are no submission / handling / publication charges.

All manuscripts written in English should be submitted as MS-Word file attachments via e-mail to editoffice@agriscitech.eu. Manuscripts must be prepared strictly in accordance with the detailed instructions for authors at the website

www.agriscitech.eu and the instructions on the last page of the journal. For each manuscript the signatures of all authors are needed confirming their consent to publish it and to nominate on author for correspondence.

They have to be presented by a submission letter signed by all authors. The form of the submission letter is available upon from request from the Technical Assistance or could be downloaded from the website of the journal. Manuscripts submitted to this journal are considered if they have submitted only to it, they have not been published already, nor are they under consideration for publication in press elsewhere. All manuscripts are subject to editorial review and the editors reserve the right to improve style and return the paper for rewriting to the authors, if necessary. The editorial board reserves rights to reject manuscripts based on priorities and space availability in the journal.

The journal is committed to respect high standards of ethics in the editing and reviewing process and malpractice statement. Commitments of authors related to authorship are also very important for a high standard of ethics and publishing. We follow closely the Committee on Publication Ethics (COPE), http://publicationethics.org/resources/guid elines

The articles appearing in this journal are indexed and abstracted in: DOI, EBSCO Publishing Inc., AGRIS (FAO) and DOAJ.

The journal is accepted to be indexed with the support of a project № BG051P00013.3.05-0001 "Science and business" financed by Operational Programme "Human Resources Development" of EU. The title has been suggested to be included in SCOPUS (Elsevier) and Electronic Journals Submission Form (Thomson Reuters).

The journal is freely available without charge to the user or his/her institution. Users can read, download, copy, distribute, print, search, or link to the full texts of the articles, or use them for any other lawful purpose, without asking prior permission from the publisher or the author.

This issue is printed with the financial support by Contract No DNP 0521/20.12.2016, financed from Fund 'Scientific Research' grant Bulgarian scientific Periodicals.

\section{Address of Editorial office:}

Agricultural Science and Technology Faculty of Agriculture, Trakia University

Student's campus, 6000 Stara Zagora

Bulgaria

Telephone: +35942699330 $+35942699446$

www.agriscitech.eu

Technical Assistance:

Nely Tsvetanova

Telephone: +359 42699446

E-mail:editoffice@agriscitech.eu 


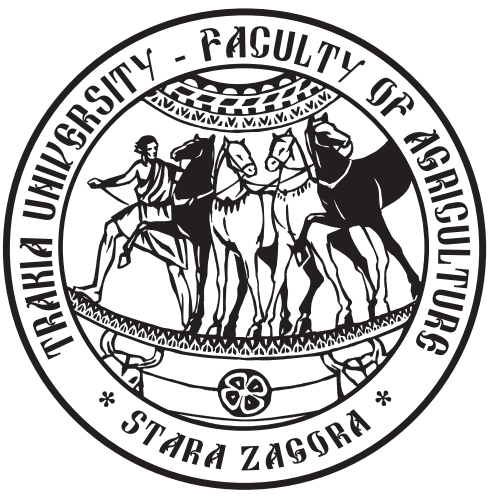

AGRICULTURAL

SCIENCE AND TECHNOLOGY

\section{7}

An International Journal Published by Faculty of Agriculture,

Trakia University, Stara Zagora, Bulgaria 


\title{
Study on the loss of accuracy of AC-method for milk yield control in sheep
}

\author{
D. Dimov*, P. Zhelyazkova, A. Vuchkov \\ Department of Animal Sciences, Faculty of Agronomy, Agricultural University, 4000 Plovdiv, Bulgaria
}

(Manuscript received 30 June 2017; accepted for publication 5 September 2017)

\begin{abstract}
The aim of this study was to investigate the loss of accuracy of AC-method for milk yield control in sheep under the conditions of threefold milking per day. Test day milk yield records of 113 ewes raised on sheep farm of the Agricultural University in Plovdiv collected according to official A4 method were used. Two breeds were raised at the university experimental farm: White Maritza (49 ewes) and Patch Faced Maritza (64 ewes). Predicted milk yield data on test day were simulated using different prediction coefficients (calculated at morning, noon or evening milk recording). Database includes 2577 predicted milk yield records on test day. The loss of accuracy using AC method is accumulated in two ways: by milk yield prediction coefficients on test day and milk yield calculations during milking period. Loss of accuracy $\left(L A_{1}\right)$ in prediction of test day milk yield by prediction coefficients varies from $10.02 \%$ to $12.74 \%$ according to type of milk recording (morning, noon or evening). Three factors such as level of test day milk yield, type of milk recording and animal have larger influence on $L A_{1}, 27.70 \%, 21.99 \%$ and $19.32 \%$, respectively, of total variation. Loss of accuracy $\left(L A_{2}\right)$ in the calculated total milked milk per milking period on the basis of predicted test day milk yield according to the morning, noon and evening milk recordings compared with $A 4$ method are $7.04 \%, 8.03 \%$ and $6.05 \%$, respectively. Depending on the type of milk recording on the test day (morning, noon and evening), $46.88 \%$ to $56.15 \%$ of the observations of $L A_{2}$ fall within the scope of $\pm 5 \%$. Rank correlations in the ranking of ewes in all years and different designs of $A C$ method have high values from 0.891 to 1.000 .
\end{abstract}

Keywords: loss of accuracy, milk yield, recording, AC-method, sheep breeding

\section{Introduction}

In many European countries where dairy sheep breeding is well developed milking is twice a day. Machine milking in sheep nowadays is common practice in many countries in the world, especially in intensive dairy sheep production systems. Therefore, milk recording in these systems is routine. Nevertheless, in many extensive sheep production systems in Europe milking is still by hand for numerous reasons. Lots of sheep farmers in the Balkan countries are still practicing milking by hand sometimes threefold a day. Some of the farmers who raise dairy or dual sheep breeds are practising threefold hand milking a day have also been included in the milk recording schemes.

The cost of milk recording in sheep, expressed in units of outcome per animal is about 2 or 3 times higher than dairy cattle milk recording (Sanna and Casu, 1999). This was the reason to seek new ways and methods in dairy sheep breeding to simplify the standard A4 method and to reduce the cost of milk recording in sheep. AT and AC methods of milk recording in sheep are approved simplified methods by International Committee of Animal Recording (Barillet et al., 1992). Astruc and Barrillet (2000) reported that till 2000 the standard A4 method for milk recording in sheep was replaced by AC and AT methods. These are simplified methods in which measuring of milk yield is performed only at one of the two milkings on the test day (TD). The interval of $30 \pm 3$ days has been accepted as standard interval between successive TDs in the milking period when AC and AT methods are applied (Barillet et al., 1992). The milk yield in TD is calculated by doubled volume of milk yield during the morning or evening milking (AT method) or using prediction coefficient (AC method).

The ICAR regulations are not giving clear guidelines as to at which milking milk recording in sheep has to be made when the situation is threefold milking a day. Then the logical question arises in which milk recording on the TD (morning, noon or evening) loss of accuracy is less?

Simplified AT and AC methods have been tested for accuracy by many authors under the conditions of double milking per day (Sanna and Casu, 1999; Ghita et al., 2007; Ivanova 2013; Pachinovski et al., 2015) and others under the conditions of threefold milking per day (Gievski et al., 2006, Pacinovski et al., 2017). The AC method decreases by $50 \%$ the necessary work to measure milk yield and that's the reason why most countries in Europe switched to using the AC method (Ghita et al., 2007). Sanna and Casu (1999) have checked accuracy and precision of simplified AT and AC methods by comparing the average difference between estimated (predicted) and reference daily milk yields. Under the conditions of double milking per day the authors find that the AC method exhibits rank correlations close to 0.99 with reference yield, revealing loss of accuracy slightly greater than the recorded for the AT method. The AC method had a slightly lower accuracy and precision than the AT, but it can give a considerable flexibility to milk recording in sheep.

The loss of accuracy (LA) of the AC method depends of how much exactly the prediction coefficients predict test day milk yields (TDMYs) and how the loss of accuracy in prediction of TDMYs reflects on the accuracy of calculations for total milked milk (TMM) during the milking period.

Analysing averaged differences between predicted and actual individual TDMYs in sheep under the conditions of threefold milking per day, Gievski et al. (2006) found out that practically three predicting coefficients (morning, noon and evening) gave very small differences between the averaged predicted and actual yields, but when considered minimum and maximum deviations for a particular ewe the results showed extreme differences from $-67.1 \%$ to $+81.3 \%$ compared to actual daily yield. The distribution of relative deviations

*e-mail: doytcho.dimov@gmail.com 
of predicted and the actual test day yields in this study illustrated that small part of the loss of accuracy observations were within the scope of $\pm 5 \%$ (from $26.2 \%$ to $33.8 \%$ depending of milk recording type). Pacinovski et al. (2017) assume that differences between the predicted and actual measured daily milk yield in the scope of $7-10 \%$ can be taken as good accuracy for prediction.

The aims of this study were to investigate loss of accuracy in prediction of test day milk yields in sheep by different prediction coefficients calculated at morning, noon or evening milk recording during the test days (threefold milking per day) and to estimate loss of accuracy in calculated total milked milk per milking period in sheep.

\section{Material and methods}

In this study 859 TDMY data recorded by A4 method on the experimental farm of Agricultural University in Plovdiv collected during five years (1997, 1998, 1999, 2000 and 2003) were used. The two sheep breeds were kept in two small flocks: White Maritza (49 ewes) and Patch Faced Maritza (64 ewes). In order to estimate the loss of accuracy (LA) of AC method two approaches were used: loss of accuracy $\left(L A_{1}\right)$ in predicted test day milk yield (PTDMY) and loss of accuracy $\left(\mathrm{LA}_{2}\right)$ in calculated TMM during milking period. Actual test day milk yield (ATDMY) data were used to simulate PTDMY data by different prediction coefficients calculated at morning, noon or evening milk recording on the TD. The prediction coefficient on the TD sometimes called flock coefficient is the ratio of total milk yield of the flock on TD to total milk yield of the flock in the milk recording milking that may be morning, noon or evening milking. Common database includes 2577 PTDMY records of 113 ewes under the conditions of threefold hand milking per day. Test day milk yields recorded in late milking period, when ewes were milked twice or once a day, were discarded. The interval between successive test days in the course of the milking period in this study was 15 days. The LA, was calculated as relative difference between PTDMY and ATDMY of particular ewe depending on morning, noon or evening prediction coefficients.

\section{$\mathrm{LA}_{1}=[($ PTDMY - ATDMY $) /$ ATDMY $] .100$}

where: LA $_{1}$ - individual loss of accuracy in PTDMY, \%; PTDMY predicted test day milk yield using morning, noon or evening prediction coefficients, mL;ATDMY - actual test day milk yield, mL.

The effects of farming year, month of lambing, litter size, flock test day, ewe test day, type of milk recording, level of milk yield, breed and animal on the LA, have been included in fixed linear model. In order to take into account some environmental effects on the $L A_{1}$ for data processing general linear models were used as follows:

$$
Y_{\text {in }}=\mu+x_{i}+e_{i j}
$$

where: $Y_{i j}$ - variable; $\mu$ - LS - mean, $X_{i}$ - fixed effects of animal (113), farming year (5), flock test day (10), ewe test day (10), level of test day milk yield (5), type of test day milk recording (3), month of lambing (7) and litter size (3) $e_{i j}$ - residual error.

The factor level of test day milk yield was divided into 5 levels: up to $500 \mathrm{~mL}, 501-1000 \mathrm{~mL}, 1001-1500 \mathrm{~mL}, 1501-2000 \mathrm{~mL}$ and over $2001 \mathrm{~mL}$. The environmental effects were successively analysed. To solve the equations of fixed linear model SSPS 13.0 were used.

The second aim in this study was to estimate individual loss of accuracy of calculation of TMM on the basis of PTDMYs. The centered method for lactation calculations was used to calculate TMM. The approach in formula for $L A_{1}$ was also applied to TMM per milking period $\left(\mathrm{La}_{2}\right)$.

$$
\mathrm{LA}_{2}=[(\text { TMM }- \text { ATMM }) / \text { ATMM }] .100
$$

where $\mathrm{LA}_{2}$ - loss of accuracy in calculated TMM, \%; TMM - total milked milk per milking period calculated by morning, noon or evening type of milk recording, L; ATMM - actual total milked milk per milking period, calculated by actual test day milk yield, L.

Relative differences in the formulas above were taken for data processing at their absolute values. This approach was preferred for data processing as this measure discovers more clearly the size of loss of accuracy in PTDMY and calculated TMM in sheep. In order to check changes in ranking of the ewes by TMM, when AC method is used instead of A4, Spearman's rank correlation was calculated.

\section{Results and discussion}

Threefold hand milking per day is still a common practice on many sheep farms in lowland regions in Bulgaria and other Balkan countries in particularly small and medium sheep farms. The possibility and right of sheep breeders practising threefold milking per day to take part in milk recording schemes set the question what type of milk recording is to be used. Gievski et al. (2006) suggested that in prediction of TDMY the most considerable is the importance of morning prediction coefficients followed by the evening and midday ones. The situation in different sheep farms is quite different. In practice, it is not so easy to decide which milking has to be used for milk recording in the TD in situation of threefold milking. A proper prediction of TDMY is important, but implementation of a milk recording scheme as long term practice is also very important.

Descriptive statistics of ATDMYs of two sheep breeds are presented in Table 1. The levels of test day milk yield of White Maritza sheep (741.58 mL) and Patch faced Maritza sheep (693.00 $\mathrm{mL}$ ) kept on the experimental farm of Agricultural university of Plovdiv are the typical levels of dual purpose sheep breeds. There is no significant difference between the average test day milk yields of the two sheep breeds which is the reason to combine the data in a common database in order to analyse the other environmental

Table 1. Descriptive statistics data of actual test day milk yield (ATDMY) of White Maritza and Patch faced Maritza sheep breeds kept on the experimental farm of Agricultural University in Plovdiv.

\begin{tabular}{lcccc}
\hline \hline Breeds & $\mathrm{n}$ & $\overline{\mathrm{x}} \pm \mathrm{S}_{\overline{\mathrm{x}}}$ & $\mathrm{CV}, \%$ & Significance differences \\
\hline White Maritza & 339 & $741.58 \pm 17.99$ & 55.25 & $\mathrm{~ns}$ \\
Patch Faced Maritza & 520 & $693.00 \pm 17.60$ & 46.78 & $\mathrm{~ns}$ \\
Total & 859 & $722.63 \pm 7.46$ & 52.40 & \\
\hline \hline
\end{tabular}

*CV - coefficient of variation; ns - no significant difference 
Table 2. Loss of accuracy $\left(\mathrm{LA}_{1}\right)$ in PTDMY predicted by different predicting coefficients depending on morning, evening or noon milk recording on test day.

\begin{tabular}{lccc}
\hline \hline Type of milk recording & $n$ & $\bar{x} \pm S_{\bar{x}}$ & Min $-\operatorname{Max}$ \\
\hline $\mathrm{AC}_{\mathrm{n}}$ & 859 & $12.74 \pm 0.37^{\text {ns }}$ & $0.00-75.60$ \\
$\mathrm{AC}_{\mathrm{e}}$ & 859 & $10.02 \pm 0.29^{\text {ns }}$ & $0.00-67.20$ \\
$\mathrm{AC}_{\mathrm{m}}$ & 859 & $10.49 \pm 0.33^{\text {ns }}$ & $0.00-56.67$ \\
\hline \hline
\end{tabular}

Key: LA1 - loss of accuracy; $n, e, m$ - subscripts denote type of milk recording on the test day (noon, evening, morning); PTDMY - predicted test day milk yield; $\bar{x}$ - mean; $S_{\bar{x}}$ - error of mean; ns - no significant difference between averages.

effects on loss of accuracy in PTDMY.

High coefficients of variations of ATDMYs are close to our previous studies for these breeds (Dimov, 1998, 2011). Normally, the usage of prediction coefficients to predict TDMY to a certain extent lead to loss of accuracy. It is very important to know how much is this loss of accuracy and whether it is acceptable. In this study $L_{A}$, varies from $10.02 \%$ to $12.74 \%$ (Table 2 ) according to type of milk recording (morning, noon or evening milk recording). Pachinovski et al. (2017) assume that it can be taken as good accuracy for prediction of TDMY if deviations from actual test daily milk yield are $7-10 \%$. The results in calculating LA, presented in Table 2 are slightly larger than this assumption and therefore we have analyzed influence of various factors that may have effect on $\mathrm{LA}_{1}$.

Table 2 gives the corresponding analyses of sources of variation on $\mathrm{LA}$, and shows that animal, farming year, flock test day, level of TDMY and type of test day milk recording have significant effects $(P<0.001)$. The effects of month of lambing and litter size are with lower degree of probability. The effects of breed and ewe test day are not significant.

Having in mind all significant and non-significant effects we have estimated proportion of the influence of difference factors (Table 3). Three factors such as level of test day milk yield, type of milk recording and animal have larger influence on $\mathrm{LA}_{1}, 27.70 \%$, $21.99 \%$ and $19.32 \%$, respectively, of the total variation. Farming year, month of lambing, litter size, flock test day and ewe test day comprised small part of total variation- $4.27 \%, 3.58 \%, 3.78 \%$, $2.76 \%$ and $0.74 \%$, respectively.

PTDMY is taken into account in the formula for lactation calculations about TMM. According to type of milk recordings (morning, noon or evening milking) different values of TMM have been calculated (Table 4).

Analysing different averaged values about TMM it can be pointed out that differences caused by applying different types of milk recording $\left(\mathrm{AC}_{n}, \mathrm{AC}_{\mathrm{e}}\right.$, or $\mathrm{AC}$ ) $)$ in comparison with $\mathrm{A4}$ method are not so big: from $+2.23 \mathrm{~L}$ to $-1.73 \mathrm{~L}$ for noon, evening and morning milkings. Prima facie, the lack of significant differences in comparing averaged values of TMM measured by different designs of $A C$ method has calming effect about all applications of the AC-method. However, comparisons between these groups means hiding real loss of accuracy depending on type of milk recording $\left(\mathrm{AC}_{n}, \mathrm{AC}_{\mathrm{e}}\right.$, and $\left.A C_{m}\right)$. When loss of accuracy is considered and calculated in absolutely individual deviations, it was found out in particular ewes that averaged values of $\mathrm{LA}_{2}$ at morning, noon and evening milk recordings are $7.04 \%, 8.03 \%$ and $6.05 \%$, respectively (Table 5).

That was the reason to search for a new approach to discover the detailed picture about $L A_{2}$ about calculated TMM when different types of milk recordings $\left(\mathrm{AC}_{n}, \mathrm{AC}_{\mathrm{e}}\right.$, and $\left.\mathrm{AC} \mathrm{C}_{\mathrm{m}}\right)$ are used. The variation of $\mathrm{LA}_{2}$ was divided in three different ranges: $\pm 5 \%,>-5 \%$ and $>+5 \%$ as it was done in the study by Gievski et al. (2006). Table 6 gives the distributions of different values of $\mathrm{LA}_{2}$ according to selected ranges.

The analyses of distributions of observations across to selected three ranges show a new picture of the loss of accuracy of calculated TMM. Usually, in the common practice milk recording is performed at morning milking. Sanna and Casu (1999) find out that morning milking had greater contribution to daily yields and provided better estimates revealing lower difference between predicted and actual TDMY. The distributions of $L A_{2}$ in Table 6 show that at the morning milk recording $51.54 \%$ of the observations of $L A_{2}$ fall within the scope of $\pm 5 \%$. From this point of view when the $A C$ method is implemented in the scheme of evening milk recording, it gives approximately the

Table 3. Analysis of sources of variation of LA1 and proportion of influence in PTDMY

\begin{tabular}{lrrrrc}
\hline \hline Sources of variation & \multicolumn{1}{c}{$\mathrm{df}$} & \multicolumn{1}{c}{$\mathrm{SS}$} & $\mathrm{F}$ & $\mathrm{P}$ & Proportion, $\%$ \\
\hline Animal & 112 & 34855.086 & 2.640 & $* * *$ & 19.32 \\
Breed & 1 & 4009.318 & 0.714 & $\mathrm{~ns}$ & 0.02 \\
FY & 4 & 7786.544 & 20.681 & $* * *$ & 4.27 \\
ML & 6 & 1528.158 & 2.636 & $* *$ & 3.57 \\
LS & 2 & 557.092 & 2.876 & $*$ & 3.77 \\
FTD & 9 & 5099.535 & 5.942 & $* * *$ & 2.76 \\
ETD & 9 & 715.689 & 0.819 & $n \mathrm{~ns}$ & 0.74 \\
Level of TDMY & 4 & 5107.589 & 13.417 & $* * *$ & 27.70 \\
Type of TDMR & 2 & 3628.930 & 18.966 & $* * *$ & 21.99 \\
Residual & 2428 & 186595.05 & & & 15.86 \\
Total & 2577 & 249882.991 & & & 100 \\
\hline \hline
\end{tabular}

Key: FY - farming year; ML - month of lambing; LS - litter size; FTD - flock test day; ETD - ewe test day; Level of TDMY level of test day milk yield; Type of TDMY - type of test day milk recording; $\mathrm{F}-$ Fischer criterion; $\mathrm{P}-$ degree of probability $*$ $\mathrm{p}<0.05 ; * *-\mathrm{p}<0.01 ; * * *-\mathrm{p}<0.001 ;$ ns - non significant. 
Table 4. Accuracy of total milked milk recorded by different types of AC milk recording method

\begin{tabular}{lccc}
\hline \hline \multirow{2}{*}{ Method of milk recording } & $\mathrm{n}$ & $\overline{\mathrm{X}} \pm \mathrm{S}_{\overline{\mathrm{x}}}$ & $\mathrm{T}$ \\
\cline { 3 - 4 } & & $97.64 \pm 3.52$ & 0 \\
\hline $\mathrm{A} 4$ & 113 & $99.87 \pm 3.66$ & $+2.23^{\text {ns }}$ \\
$\mathrm{AC}_{\mathrm{n}}$ & 113 & $95.91 \pm 3.50$ & $-1.73^{\text {ns }}$ \\
$\mathrm{AC}_{\mathrm{e}}$ & 113 & $95.97 \pm 3.61$ & $-1.67^{\text {ns }}$ \\
$\mathrm{AC}_{\mathrm{m}}$ & 113 & & $\mathrm{D}$ \\
\hline \hline
\end{tabular}

Key: TMM - total milked milk; $\bar{x}$ - mean; $S_{\bar{x}}$ error of mean; A4 - official standard method of milk recording in sheep; $A C$ - simplified milk recording method in sheep, $n, e, m$ - subscripts denote type of milk recording on test day (noon, evening or morning milk recording); D - difference between mean values of TMM measured by different AC methods with standard A4 method; a - superscripts denote significance $p<0.05$.

Table 5. Loss of accuracy $\left(\mathrm{LA}_{2}\right)$ in calculated TMM by different designs of $A C$ methods depending of morning, evening or noon milk recording on the test days

\begin{tabular}{lcc}
\hline \hline $\begin{array}{l}\text { Designs of } A C \text { method } \\
\text { of milk recording }\end{array}$ & $n$ & $\bar{x} \pm S_{\bar{x}}$ \\
\hline $\mathrm{AC}_{\mathrm{n}}$ & 113 & $8.03 \pm 0.58$ \\
$\mathrm{AC}_{\mathrm{e}}$ & 113 & $6.05 \pm 0.46$ \\
$\mathrm{AC}_{\mathrm{m}}$ & 113 & $7.04 \pm 0.47$ \\
\hline \hline
\end{tabular}

Key: AC - simplified milk recording method in sheep; $n, e$, $m$ - subscripts denote type of milk recording on the test day (noon, evening, morning).

same precision, because $56.15 \%$ of the observations fall within the scope of $\pm 5 \%$. Although noon milk recording is more comfortable from organisational point of view in comparison with other types of milk recordings (morning and evening), less $\mathrm{LA}_{2}$ observations fall within the acceptable scope of $\pm 5 \%$. The analysis of Table 6 shows that in the morning and evening milk recordings the MY is underestimated at $30.78 \%$ and $27.69 \%$ of the observations, respectively. Table 6 gives discover approximate estimations that not a small number of observations have a great loss of accuracy $\left(\mathrm{LA}_{2}\right)$.

In principle, the AC-method of milk recording in sheep is applied in order to obtain objective data on the milk yield in sheep. These data are used for estimations of genetic parameters, breeding values and ranking of ewes in the process of selection. The question arises whether these $L A_{1}$ and $L A_{2}$ could affect the ranking of ewes for milk yield? The answer to this question was looking for calculation of rank correlations $\left(r_{s}\right)$ depending of the type of milk recording (Table 7). Rank correlations in all years and different designs of the AC method have high values from 0.891 to 1.00 , which means that the change of ranking of ewes by TMM calculated on the basis of $A C_{n}$ $A C_{e} A C_{m}$ designs is non-significant.

Obviously, applying the AC method under the conditions of threefold milking per day is associated with loss of accuracy both for

Table 7. Rank correlations of the ranking ewes by TMM calculated by different types of milk recordings

\begin{tabular}{lrccc}
\hline \hline Year & \multicolumn{1}{c}{$n$} & $\mathrm{r}_{\mathrm{s}}$ at $\mathrm{AC}_{\mathrm{n}}$ & $\mathrm{r}_{\mathrm{s}}$ at $\mathrm{AC}_{\mathrm{e}}$ & $\mathrm{r}_{\mathrm{s}}$ at $A C_{\mathrm{m}}$ \\
\hline 1997 & 13 & 0.989 & 0.973 & 0.978 \\
1998 & 5 & 1.000 & 0.900 & 1.000 \\
1999 & 20 & 0.968 & 0.901 & 0.944 \\
2000 & 11 & 0.891 & 0.945 & 0.973 \\
2003 & 64 & 0.981 & 0.984 & 0.983 \\
\hline \hline
\end{tabular}

Table 6. Distribution of relative differences of TMM in different classes of range depending on type of AC milk recording $(n=113)$

\begin{tabular}{lccc}
\hline \hline \multirow{2}{*}{ Method } & \multicolumn{3}{c}{ Classes of relative differences, $\%$} \\
\cline { 2 - 4 } & $>-5 \%$ & $\pm 5 \%$ & $>+5 \%$ \\
\hline $\mathrm{AC}_{\mathrm{n}}$ & 17.19 & 46.88 & 35.94 \\
$\mathrm{AC}_{\mathrm{e}}$ & 27.69 & 56.15 & 23.85 \\
$\mathrm{AC}_{\mathrm{m}}$ & 30.78 & 51.54 & 18.46 \\
\hline \hline
\end{tabular}

PTDMY and TMM. Such data for milk yields in sheep accumulated as database are important for future analyses in test day models and lactation models. That's why the loss of accuracy has to be as small as possible. Significant influence of the factors animal, farming year, flock test day, daily milk level and type of test day milk recording on the loss of accuracy of PTDMY show that additional measures are necessary to decrease the influence of environmental effects on TD.

The literature review shows that many authors who have investigated the loss of accuracy of the AC method are satisfied to compare averages of milk yields in sheep obtained from the simplified AC and A4 standard methods (Sanna and Cassu, 1999, Ghita et al., 2007, Ivanova, 2013). The results of this study show that this approach cannot reveal the true loss of accuracy by using the AC method. In principle, in order to benefit from the simplified AC method, there should be no differences in the average milk yields between AC and A4 methods. The absence of a difference between the average values of the two sets shows that the simplified AC method does not displace the average of the general population, which means that the obtained average corresponds to the theoretically expected. Otherwise, the AC method cannot be used for milk recording in sheep. However, the averaging of milk yield data obtained under the simplified AC method conceals significant individual deviations. In this study we tried to analyse these otherwise unavoidable deviations. The analysis showed that the loss of accuracy is more prominent when it is expressed as an absolute value of the relative deviation of predicted test day milk yield with actual test day milk yield. Averaging of data with absolute values of individual loss-of-accuracy data ignores the meaning of the positive and negative signs, otherwise averaging a line or column of numbers with positive or negative signs reduces the arithmetic mean.

Regardless of the loss of accuracy in PTDMY and TMM caused by different factors when different designs of AC method are applied, this method has so far remained the only suitable method for milk 
recording in a sheep flock where the milking is threefold a day.

\section{Conclusion}

The implementation of $A C$ method in the situations of threefold milking a day in the sheep breeding practice is associated with some loss of accuracy. This loss of accuracy is accumulated in two ways: by the milk yield prediction coefficients on test day and by calculating this loss of accuracy in milk yield calculations during milking period. There is a tendency on test day the loss of accuracy of predicted test day milk yield to be the greatest when milk recording is done at noon milking $-12.74 \%$. Many factors such as animal, farming year, flock test day, test day milk yield and type of milk recording on test day have significant influence on the loss of accuracy of predicted test day milk yield. Three factors such as level of test day milk yield, type of milk recording and animal had larger influence on the loss of accuracy on test day and their proportions in total variation are $27.70 \%, 21.99 \%$ and $19.32 \%$, respectively. Different designs of AC method according to type of milk recording during milking period are associated with acceptable loss of accuracy $6.05 \%, 7.04 \%$ and $8.03 \%$, respectively, at evening, morning and noon milk recording. Ranking of ewes by total milked milk using the $A C$ method is insignificantly changed.

\section{References}

Astruc JM and Barillet F, 2000. Report of the working group on milk recording of sheep. Proceedings of the $32^{\text {nd }}$ Biennial Session of ICAR, Bled, Slovenia, 14-19 May 2000, EAAP Publication. No. 98, pp. 289-306.

Barillet F, Astrug JM, de Brauwer P, Casu S, Fabbri G, Federsen E, Frangos K, Gabina D., Gama LT, Ruiz Tena JL and Sana S, 1992. International regulation for milk recording in sheep. ICAR publication.

Dimov D, 1998. Description and productive traits of Patch Faced Maritza sheep. Proceedings of International conference on conservation of endangered autochthonous animal breeds of Danubian countries. Budapest, Hungary, 26 - 28 May, pp. 73-78.

Dimov D, 1998. Description and productive traits of White Maritza sheep. Proceedings of International conference on conservation of endangered autochthonous animal breeds of Danubian countries. Budapest, Hungary, 26 - 28 May, pp. 79-83.

Dimov DP, 2011. Milk yield and body weight of White Maritza sheep. Proceedings of $8^{\text {th }}$ Global conference on the conservation of Animal Genetic Resources, 4-8 October, Tekirdag, Turkey, pp. 113-115.

Ganter V, Jovanovac S and Klopcic M, 2009. Methods for estimation of daily and lactation milk yields from alternative milk recording scheme in Holstein and Simmental cattle breeds. Italian Journal ofAnimal Science, 8, 519-530.
Gievski M, Dimov G, Pacinovski N and Palasevski B, 2006. Possibilities for prediction of the test day milk yield based on only one individual test per day in Awassi sheep. Book of Abstracts of the 57th Annual Meeting of the European Association for Animal Production (EAAP). Book of abstracts, No 12, pp. 90. 17-20 September, Antalya, Turkey.

Ghanther V, Jovanovac S, Gaguz N, Clopcicq M and Solic D, 2008. Prediction of lactation milk yield using various milk recording methods. Biotechnology in Animal Husbandry, 24, 9-18.

Ghita E, Grosu H and Rebedea M, 2007. Investigations in the efficiency of using ICAR standardised methods AC and AT to record milk yield in sheep. Lucrări ştiinţifice Zootehnie şi Biotehnologii, 40, 340-347.

Gorard ST, 2004. Revisiting a 90-year-old debate: the advantages of the mean deviation. Paper presented at the British Educational Research Association Annual Conference, University of Manchester, 16-18 September 2004. (http://www.leeds. ac.uk/educol/documents/00003759.htm).

Hassen Sayed SZ, 2006. Measurement \& Error. Department of Electrical \& Electronic Engineering University of Mauritius. January 30.

ICAR, 2012. Procedure proposed for quality assurance regarding AC method. Working group on performance recording of dairy sheep. Cork, May 29, 2012.

International Committee of Animal Recording, 2012. International Agreement of Recording Practices. Guidelines approved by the General Assembly held in Corck, Ireland, June.

Ivanova T, 2013. Milk production of sheep of Bulgarian synthetic population in flock of Institute of animal sciences in Kostinbrod. Thesis for PhD, Agricultural academy, Institute of Animal Sciences, Kostinbrod (Bg).

Pacinovski N, Džabirski V, Porču K, Dimov G, Cilev G, Antunović ZV and Trajkovski G, 2015. Simplification of A4 to AC4 method of test day yield of east Friesian sheep in Macedonia. Macedonian Journal of Animal Science, 5, 51-58.

Pacinovski N, Džabirski V, Porču K and DIMOV G, 2017. The accuracy of $A 4$ and $A C$ methods for determining lactation in control day in threefold milking of Awassi breed of sheep (In press).

Silva Pereira M and Oliveira T, 2006. Multiple regression models for lactation curves. In SCRA 2006 2006-FIM XIII-Thirteenth International Conference of the Forum for Interdisciplinary Mathematical and Statistical Techniques September 1-4, 2006, New University of Lisbon - Tomar Polytechnic Institute Lisbon, Portugal.

Sana SR and Casu S, 1999. Use of simplified milk recording schemes in dairy sheep. Proceeding of the A.S.P.A. XIII Congress, Piacenza, June 21-24.

Tangorra FM, Zaninelli M, Bruni G, Zanatta G and Mercandino L, 2008. Comparison among actual and estimated milk yields in dairy goats. International Conference "Innovation Technology to Empower Safety, Health and Welfare in Agriculture and Agro-food Systems" September 15-17, Ragusa, Italy. 


\section{Genetics and Breeding}

Variation in the agronomic and morphological traits in spring barley

N. Dyulgerov, B. Dyulgerova

Study on the loss of accuracy of AC method for milk yield control in sheep

D. Dimov, P. Zhelyazkova, A. Vuchkov

Hordein polymorphism between spring barley cultivars by SDS-PAGE electrophoresis

N. Neykov, S. Doneva

\section{Nutrition and Physiology}

Comparative study of rapeseed, monofloral types and multifloral honey by some physico-chemical parameters

I. Zhelyazkova, S. Lazarov

Body condition score, nonesterified fatty acids and beta-hydroxybutyrate concentrations in goats with subclinical ketosis

V. Marutsova, R. Binev

\section{Production Systems}

Lucrative status of improved dual purpose cowpea (Vigna unguiculata L., Walp) in Damboa, Borno State, North-Eastern Nigeria

B.H. Gabdo

Study on the emptying time of grain harvester hoppers

K. Trendafilov, N. Delchev, B. Kolev, G. Tihanov

Length of the growing season and yield in Triticum monococcum L., in accordance with the growing conditions

S. Stamatov, E. Valchinova, G. Desheva, K. Uzundzhalieva, P. Chavdarov, T. Cholakov, B. Kyosev, R.

Ruseva, N. Velcheva

Productivity of durum wheat cultivar Predel at nitrogen-phosphorous fertilization

L. Plescuta

Effect of the herbicide treatment dose on the weed infestation in common winter wheat

Z. Petrova

Evaluation of some technological properties of Caucasian ram wool

D. Pamukova, G. Staykova, N. Stancheva, D. Panayotov 


\section{Agriculture and Environment}

Saved $\mathrm{CO}_{2}$ emissions by using renewable sources for hot water yield in Bulgarian dairy farms

R. Georgiev, R. Slavov, K. Peychev, D. Georgiev, S. Apostolov, J. Ellingsen, J. Tønnesen

Inventory of the legal base for reclamation of lands disturbed by open-cast mining in Bulgaria

M. Banov, V. Tzolova, I. Kirilov

Taxonomic composition of phytoplankton in Black Sea area in front of the Cape Galata (2008-2016)

D. Klisarova, D. Gerdzhikov

Biodiversity of the macrozoobenthos in some protected marine areas along Bulgarian Black Sea coast

E. Petrova, S. Stoykov

Heavy metals in organs of gudgeon (Gobio gobio L.) from Vardar River, R. Macedonia

R. Nastova, V. Kostov, I. Uslinovska

Product Quality and Safety

Mathematical methods for assessment and analysis of honey yield data for Bulgaria and the

N. Keranova

Carcass traits and meat quality of different slow growing and fast growing broiler chickens

M. Oblakova, N. Mincheva, P. Hristakieva, I. Ivanova, M. Lalev, Sv. Georgieva

Role and importance of the awareness for whey in dairy sector at an international level 


\section{Instruction for authors}

\section{Preparation of papers}

Papers shall be submitted at the editorial office typed on standard typing pages (A4, 30 lines per page, 62 characters per line). The editors recommend up to 15 pages for full research paper ( including abstract references, tables, figures and other appendices)

The manuscript should be structured as follows: Title, Names of authors and affiliation address, Abstract, List of keywords, Introduction, Material and methods, Results, Discussion, Conclusion, Acknowledgements (if any), References, Tables, Figures.

The title needs to be as concise and informative about the nature of research. It should be written with small letter /bold, 14/ without any abbreviations.

Names and affiliation of authors The names of the authors should be presented from the initials of first names followed by the family names. The complete address and name of the institution should be stated next. The affiliation of authors are designated by different signs. For the author who is going to be corresponding by the editorial board and readers, an E-mail address and telephone number should be presented as footnote on the first page. Corresponding author is indicated with *

Abstract should be not more than 350 words. It should be clearly stated what new findings have been made in the course of research. Abbreviations and references to authors are inadmissible in the summary. It should be understandable without having read the paper and should be in one paragraph.

Keywords: Up to maximum of 5 keywords should be selected not repeating the title but giving the essence of study.

The introduction must answer the following questions: What is known and what is new on the studied issue? What necessitated the research problem, described in the paper? What is your hypothesis and goal?

Material and methods: The objects of research, organization of experiments, chemical analyses, statistical and other methods and conditions applied for the experiments should be described in detail. A criterion of sufficient information is to be possible for others to repeat the experiment in order to verify results.

Results are presented in understandable tables and figures, accompanied by the statistical parameters needed for the evaluation. Data from tables and figures should not be repeated in the text. Tables should be as simple and as few as possible. Each table should have its own explanatory title and to be typed on a separate page. They should be outside the main body of the text and an indication should be given where it should be inserted.

Figures should be sharp with good contrast and rendition. Graphic materials should be preferred. Photographs to be appropriate for printing. Illustrations are supplied in colour as an exception after special agreement with the editorial board and possible payment of extra costs. The figures are to be each in a single file and their location should be given within the text.

Discussion: The objective of this section is to indicate the scientific significance of the study. By comparing the results and conclusions of other scientists the contribution of the study for expanding or modifying existing knowledge is pointed out clearly and convincingly to the reader. Conclusion: The most important consequences for the science and practice resulting from the conducted research should be summarized in a few sentences. The conclusions shouldn't be numbered and no new paragraphs be used. Contributions are the core of conclusions. References:

In the text, references should be cited as follows: single author: Sandberg (2002); two authors: Andersson and Georges (2004); more than two authors: Andersson et al.(2003). When several references are cited simultaneously, they should be ranked by chronological order e.g.: (Sandberg, 2002; Andersson et al., 2003; Andersson and Georges, 2004).

References are arranged alphabetically by the name of the first author. If an author is cited more than once, first his individual publications are given ranked by year, then come publications with one co-author, two co-authors, etc. The names of authors, article and journal titles in the Cyrillic or alphabet different from Latin, should be transliterated into Latin and article titles should be translated into English. The original language of articles and books translated into English is indicated in parenthesis after the bibliographic reference $($ Bulgarian $=\mathrm{Bg}$, Russian $=\mathrm{Ru}$, Serbian $=\mathrm{Sr}$, if in the Cyrillic, Mongolian =
Mo, Greek = Gr, Georgian = Geor., Japanese $=\mathrm{Ja}$, Chinese $=\mathrm{Ch}$, Arabic $=\mathrm{Ar}$, etc.)

The following order in the reference list is recommended:

Journal articles: Author(s) surname and initials, year. Title. Full title of the journal, volume, pages. Example:

Simm G, Lewis RM, Grundy B and Dingwall WS, 2002. Responses to selection for lean growth in sheep. Animal Science, 74, 39-50

Books: Author(s) surname and initials, year. Title. Edition, name of publisher, place of publication. Example:

Oldenbroek JK, 1999. Genebanks and the conservation of farm animal genetic resources, Second edition. DLO Institute for Animal Science and Health, Netherlands.

Book chapter or conference proceedings: Author(s) surname and initials, year. Title. In: Title of the book or of the proceedings followed by the editor(s), volume, pages. Name of publisher, place of publication. Example:

Mauff G, Pulverer G, Operkuch W, Hummel K and Hidden C, 1995. C3variants and diverse phenotypes of unconverted and converted C3. In: Provides of the Biological Fluids (ed. $\mathrm{H}$. Peters), vol. 22, 143-165, Pergamon Press. Oxford, UK.

Todorov N and Mitev J, 1995. Effect of level of feeding during dry period, and body condition score on reproductive performance in dairy cows, IX $X^{\text {th }}$ International Conference on Production Diseases in Farm Animals, September 11-14, Berlin, Germany.

Thesis:

Hristova D, 2013. Investigation on genetic diversity in local sheep breeds using DNA markers. Thesis for PhD, Trakia University, Stara Zagora, Bulgaria, (Bg).

The Editorial Board of the Journal is not responsible for incorrect quotes of reference sources and the relevant violations of copyrights.

\section{Animal welfare}

Studies performed on experimental animals should be carried out according to internationally recognized guidelines for animal welfare. That should be clearly described in the respective section "Material and methods". 


\section{AGRICULTURAL \\ SCIENCE AND TECHNOLOGY}

Volume 9, Number 4 December 2017
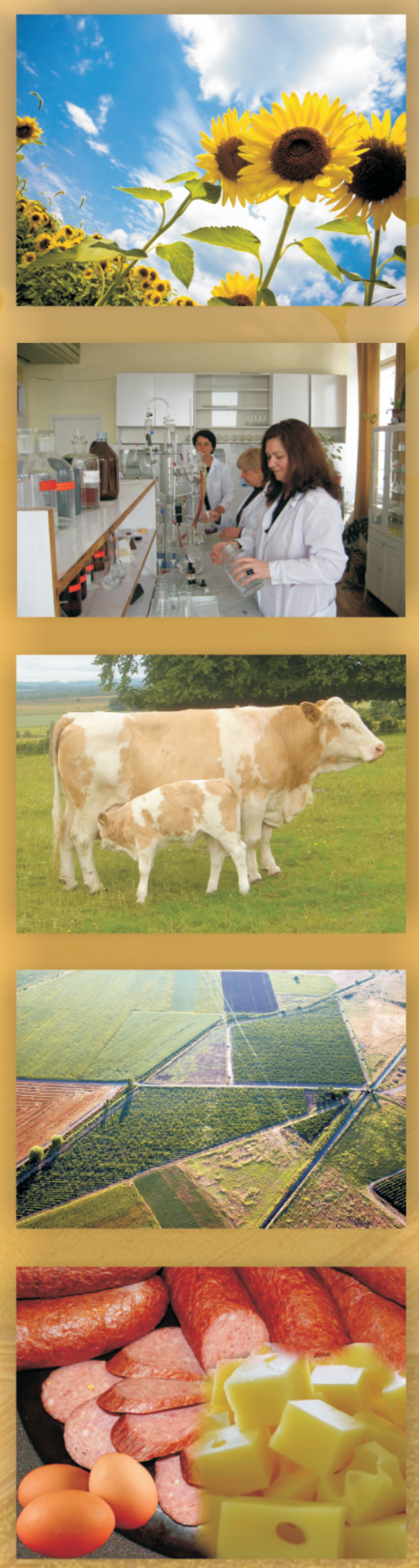

Journal web site: 